\title{
Autism associated with low 5-hydroxyindolacetic acid in CSF and the heterozygous SLC6A4 gene Gly56Ala plus 5-HTTLPR L/L promoter variants
}

\author{
Dea Adamsen $^{\text {a,c,e }}$, David Meili ${ }^{\text {a,c }}$, Nenad Blau ${ }^{\text {a,c,d,e }}$, Beat Thöny ${ }^{\text {a,c,d,e,* }}$, Vincent Ramaekers ${ }^{\text {b,* }}$ \\ a Division of Chemistry and Biochemistry, Department of Pediatrics, University of Zürich, Switzerland \\ ${ }^{\mathrm{b}}$ Centre of Autism Liège and Division of Pediatric Neurology, University Hospital Liège, Belgium \\ c Centre for Neuroscience (ZNZ), Zürich, Switzerland \\ ${ }^{\mathrm{d}}$ Integrative Human Physiology (ZIHP), Zürich, Switzerland \\ e Pediatric Research Centre (PRC), Zürich, Switzerland
}

\section{A R T I C L E I N F O}

\section{Article history:}

Received 1 October 2010

Received in revised form 18 November 2010

Accepted 18 November 2010

Available online 29 November 2010

\section{Keywords:}

Serotonin

CNS

Atypical autism

SLC6A4

\begin{abstract}
A B S T R A C T
The known Gly56Ala mutation in the serotonin transporter SERT (or 5-HTT), encoded by the SLC6A4 gene, causes increased serotonin reuptake and has been associated with autism and rigid-compulsive behavior. We report a patient with macrocephaly from birth, followed by hypotonia, developmental delay, ataxia and a diagnosis of atypical autism (PDD-NOS) in retrospect at the age of $4 \frac{1}{2}$ years. Low levels of the serotonin endmetabolite 5-hydroxyindolacetic acid (5HIAA) in CSF were detected, and SLC6A4 gene analysis revealed the heterozygous Gly56Ala alteration and the homozygous 5-HTTLPR L/L promoter variant. These changes are reported to be responsible for elevated SERT activity and expression, suggesting that these alterations were responsible in our patient for low serotonin turnover in the central nervous system (CNS). Daily treatment with 5-hydroxytryptophan (and carbidopa) led to clinical improvement and normalization of 5HIAA, implying that brain serotonin turnover normalized. We speculate that the mutated 56Ala SERT transporter with elevated expression and basal activity for serotonin re-uptake is accompanied with serotonin accumulation within pre-synaptic axons and their vesicles in the CNS, resulting in a steady-state of lowered serotonin turnover and degradation by monoamine-oxidase (MAO) enzymes in pre-synaptic or neighboring cells.
\end{abstract}

(c) 2010 Elsevier Inc. All rights reserved.

\section{Introduction}

Autism is a childhood-onset disorder with neuro-developmental abnormalities in early life leading to severe defects in social interaction, communication and limited activities with repetitive stereotypic behavior or movements [1]. The Autism Spectrum Disorders (ASD) include besides the "typical" Kanner autism, Asperger's syndrome and the atypical forms of autism, also known as pervasive developmental disorder - not otherwise specified (PDD-NOS). In more than $25-50 \%$ of individuals suffering from ASD and their first-degree relatives, whole blood serotonin levels were found to be elevated due to increased serotonin storage within platelets [2,3]. In addition, functional neuro-imaging studies using positron emission tomography (PET) have shown diminished serotonin synthesis in children with autism between the age of 2 and 5 years, as

\footnotetext{
* Corresponding authors. Ramaekers is to be contacted at Centre of Autism Liege and Division of Pediatric Neurology, University Hospital Liege, Quai Godefroid Kurth 45, 4020 Liège, Belgium. Fax: +32 4 2703292. Thöny, Division of Clinical Chemistry and Biochemistry, Department of Pediatrics, University of Zürich, Steinwiesstrasse 75, CH8032 Zürich, Switzerland. Fax: +4144266 7169.

E-mail addresses: beat.thony@kispi.uzh.ch (B. Thöny), vramaekers@skynet.be (V. Ramaekers).
}

well as the focal aberrations of serotonin synthesis and the low binding potentials of the serotonin transporter and receptor in individuals with ASD $[4,5]$. Short-term dietary depletion of tryptophan (i.e. the serotonin precursor) has been shown to exacerbate repetitive behavior and to elevate anxiety and feelings of unhappiness in autistic individuals [6]. In contrast, treatment with selective serotonin re-uptake inhibitors commonly used antidepressants - interacts pharmacologically with the serotonin transporter SERT (or 5-HTT) and has been shown to be effective in ameliorating the repetitive and/or obsessive behavior and interests in some but not all autistic individuals [7].

The serotonin transporter SERT or 5-HTT, encoded by the SLC6A4 gene, is thought to play a prominent role in serotonin homeostasis in primates and non-human primates, and several gene variants that may change the structure or function of the transporter protein were associated with autism [8]. Among them, polymorphisms within the 5HTTLPR promoter sequence, mutations in the coding sequence, or intronic mutations of this serotonin transporter were reported to be linked to autism by some studies, but other studies have been inconclusive [8-10]. The SLC6A4 5-HTTLPR promoter sequence, located about $1 \mathrm{~kb}$ upstream of the transcription initiation site, contains two variable repeat length polymorphisms known as the long (L) with 16 repeat elements, or the $44 \mathrm{bp}$ shorter (S) variant with 14 repeat 
elements [11,12], which determines a different expression of the serotonin transporter in pre-synaptic axonic membranes. The $\mathrm{L} / \mathrm{L}$ genotype of this 5 -HTTLPR promoter variant expresses significantly (1.4-1.5 fold) more transporter protein as compared to the $\mathrm{L} / \mathrm{S}$ or $\mathrm{S} / \mathrm{S}$ variants [13]. As a consequence, the $\mathrm{L} / \mathrm{L}$ variant was proposed to lead to a lowered concentration of serotonin in the synaptic cleft, although contradictory reports regarding the role of 5-HTTLPR variations exist (see e.g. [14]). In addition to these non-coding variants in the promoter region, a number of mutations in the coding region modulate SERT activity [10]. Among them, the non-synonymous variant Gly56Ala in exon 3 of the SLC6A4 gene was reported to be autism-associated and showed constitutively elevated SERT activity [15]. This glycine to alanine exchange at position 56 is located in the N-terminal intracellular tail of the SERT-protein. Pharmacological studies of serotonin re-uptake by EBV-transformed lymphocytes expressing the heterozygous Gly56Ala or homozygous 56Ala protein mutants indicated a progressive gain of function by 1.4 or 1.8 fold, respectively, compared to cells expressing the wild-type SERT (Gly56) [15]. Another known variant of the SLC6A4 gene, which potentially modulates serotonin transport function, is a variable number of tandem repeat (VNTR) polymorphism in intron 2, STin2.9, STin2.10, and STin2.12, containing 9,10 and 12 copies of the VNTR element, respectively $[8,16]$.

The in vitro findings of increased serotonin re-uptake by the heterozygous SERT mutation 56Ala by pre-synaptic axons will be expected to enhance both serotonin recycling into vesicles and degradation by monoamine-oxidase (MAO) enzymes to the 5HIAA end-metabolite. 5HIAA measurements in CSF are thought to provide an accurate and comparable parameter for extra-cellular brain serotonin levels [17]. However, the adaptive changes with respect to serotonin autoreceptor expression, release of serotonin and its de novo synthesis remain unknown. Our report on a patient with atypical autism and speech delay carrying the heterozygous Gly56Ala allele of the SLC6A4 gene in combination with the 5-HTTLPR L/L promoter variant documents for the first time findings of low 5HIAA in CSF and response to therapeutic intervention with 5-hydroxytryptophan/ carbidopa with clinical improvement and normalization of 5HIAA in CSF, indicative of normal serotonin turnover in the brain.

\section{Subjects and methods}

\subsection{Case report}

This patient described here was reported in a previous paper (patient CM; number 3; [18]) as a boy from healthy, nonconsanguineous parents, born after an uneventful prenatal period with a birth weight of $3450 \mathrm{~g}, 52 \mathrm{~cm}$ body length and $38 \mathrm{~cm}$ head circumference. After a normal neonatal period, the boy was described as a floppy infant during the first months, and his history revealed macrocephaly at and from birth with hypotonia and moderate delay of acquisition of motor milestones. He was able to pull himself to stand at 20 months and started to walk with an ataxic gait from the age of $2 \frac{1}{2}$ years. His development was marked by psychomotor retardation with speech delay and development of a hypotonic-ataxic syndrome at the age of $3 \frac{1}{2}$ years. In retrospect, a diagnosis of atypical autism at the age of $4 \frac{1}{2}$ years was suspected and could be confirmed recently as a review of the patient's history. The patient fulfilled the DSM-IV criteria for atypical autism (or PDD-NOS), being at that time all criteria of qualitative impairment of social interaction (4 items), all criteria for qualitative impairment in verbal and non-verbal communication (4 items), but lack of the criteria for restricted repetitive and stereotyped patterns of behavior, interests and activities, as manifested by 4 items. Before the age of $41 / 2$ years, he also had expressive speech delay as mentioned and did not show symbolic or imaginative play with severely disrupted social interaction and his condition could not be better accounted for by other neurological disorders. In summary, these manifestations comply with atypical autism at the age of $4 \frac{1}{2}$ years. Other testing like ADOS, ADI-R or CARS has not been performed at that time.

As mentioned before, the patient has been reported in a previous paper (patient number 3; [18]), describing five boys suffering from a novel neuro-developmental condition with psychomotor delay and a hypotonic-ataxic syndrome. All five patients had isolated low 5HIAA levels in CSF and responded to treatment with the serotonin precursor 5-hydroxytryptophan and the peripheral decarboxylase inhibitor carbidopa. Side-effects have never been reported. Following treatment with 5-hydroxytryptophan from the age of $4 \frac{1}{2}$ years, the here presented patient started to improve his motor skills and gait, fell less frequently and became able to use stairways. Much of improvement of his motor skills related to diminution of ataxic signs and better muscle tone. About 4 months after treatment the parents noticed that he started to utter sounds and attempted to speak single words and tried to add gestures to communicate to his brother and parents. From the age of $5 \frac{1}{2}$ years carbidopa was added to 5 -hydroxytryptophan. He soon started to speak and communicate with interest in social interaction with his peers and other persons. The parents described as if he awakened from his own world. At the age of 5.9 years he had still an expressive language disorder and a non-verbal IQ test estimated his IQ between 80 and 90 [19]. The now nearly 17 year-old boy continued to receive treatment of 5-hydroxytryptophan and carbidopa from the age of $4 \frac{1}{2}$ years.

Although a central disorder of serotonin synthesis or low serotonin turnover was suspected, further genetic analysis of the genes encoding the neuronal and peripheral tryptophan hydroxylase genes was normal. Extensive investigations were normal, including neurophysiological studies, neuro-imaging, metabolic and genetic testing.

\subsection{Methods}

Lumbar puncture was performed according to a fixed protocol between 8:30 and 10:00 a.m. as described previously for determination of the biogenic amine metabolites, pterins and 5-methyltetrahydrofolate $[20,21]$. A fasting amino-acid analysis in plasma and CSF was performed on the patient.

After parental informed consent for the boy, an oral dose of 5hydroxytryptophan was started. At the age of $4 \frac{1}{2}$ years, the child was put on a normal diet, excluding tryptophan rich nutrients, and 24-hour urinary 5HIAA excretion was measured before and after a low testing dose of 5-hydroxytryptophan at $1 \mathrm{mg} / \mathrm{kg} /$ day (tid) after hospital admission. Simultaneously, clinical tolerability during his stay in hospital was tested using a regular check-up of his general and neurological status as well as continuous monitoring of cardiopulmonary and circulatory parameters. Thereupon, oral treatment by 5-hydroxytryptophan was slowly increased at biweekly intervals with increments of 0.5 to $1 \mathrm{mg} / \mathrm{kg}$ / day (tid), up to a maximum daily dose of $7 \mathrm{mg} / \mathrm{kg}$ (tid) with regular verification of his clinical response and adverse side-effects. During treatment at this maximum 5-hydroxytryptophan dose, a lumbar puncture was repeated at the age of 5.2 years to check his spinal fluid 5HIAA levels. As spinal fluid 5HIAA and 5-hydroxytryptophan levels had remained low, we decided to reduce the 5-hydroxytryptophan dose by $30 \%$ to $5 \mathrm{mg} / \mathrm{kg} /$ day (tid) and added a low dose of carbidopa at $1 \mathrm{mg} / \mathrm{kg} /$ day (tid) from the age of 51/2years. During combined treatment with 5 hydroxytryptophan and carbidopa a CSF sample was repeated at the age of 5.9 years.

Genetic analysis included genomic DNA sequence analysis from various genes (see below). For the SLC6A4 gene, we additionally investigated the 5-HTTLPR promoter variants and the intronic (intron 2) STin2 VNTR polymorphisms. All exons and exon-intron boundaries were sequenced from the following genes: tryptophan hydroxylases type 1 and 2 (TPH1, MIM\# 191060, ENST0000250018; TPH2, MIM\# 607478, ENST00000333850), GTP cyclohydrolase I feedback regulatory protein (GCHFR, MIM\# 602437, ENST00000260447) and serotonin transporter (SLC6A4, MIM\# 182138, ENST00000394821). More detailed 
information on the molecular analysis of the SLC6A4 gene, including the 5 -HTTLPR and STin2 VNTR, is given in "Supporting information" and in Table S1.

\section{Results}

The CSF findings for our patient are depicted in Table 1 (see also reference [18]). The only aberrant baseline value for the metabolites analyzed was the lowered 5HIAA value in the presence of normal 5hydroxytryptophan and tryptophan levels. The values for the catecholamine pathway metabolites L-dopa, 3-O-methyldopa and homovanillic acid (HVA), as well as the pterin metabolites (biopterin, neopterin) and 5-methyltetrahydrofolate were normal (not shown). The low 5HIAA value explained the elevated HVA/5HIAA ratio. A twenty-four hours urinary collection on a diet excluding food products with a high tryptophan content detected a low daily 5HIAA urinary excretion of $5 \mu \mathrm{mol}$ (reference range $10-50 \mu \mathrm{mol} /$ day), which normalized to a normal daily excretion of $71 \mu \mathrm{mol}$ after an oral load of 5-hydroxytryptophan at $1 \mathrm{mg} / \mathrm{kg}$ body weight/day (divided in three daily doses).

A slowly titrating oral dose in the patient was started up to a final daily dose of $7 \mathrm{mg} / \mathrm{kg}$ 5-hydroxytryptophan, and from the age of $51 / 2$ years we reduced 5-hydroxytryptophan to $5 \mathrm{mg} / \mathrm{kg}$ and added $1 \mathrm{mg} / \mathrm{kg}$ carbidopa, divided into three equal doses. Clinical recovery resulted first in disappearance of hypotonia and ataxia, later followed by slow disappearance of autistic features and amelioration of speech and cognitive skills. However, speech delay persisted. Follow-up CSF analysis during oral substitution with 5-hydroxytryptophan alone ( $7 \mathrm{mg} / \mathrm{kg} /$ day) did not show normalization of CSF 5HIAA but addition of carbidopa showed normalization of 5HIAA values and the HVA/ 5HIAA ratio (see Table 1 ).

The isolated low serotonin metabolite 5HIAA in the CSF prompted us to investigate by a candidate gene approach factors that might be specifically involved in the metabolism or transport of serotonin. Among them, we tested for alterations in the TPH1 and 2 genes, as well as the gene encoding the GTP-cyclohydrolase I feedback regulatory protein (GFRP, GCHFR gene). Whereas both tetrahydrobiopterindependent TPH isoforms are rate limiting enzymes for serotonin biosynthesis [22,23], the GFRP was reported to be expressed in specific brain tissues and potentially be involved in the regulation of tetrahydrobiopterin biosynthesis in serotonin (but not dopamine) neurons [24]. Only wild-type sequences were found for the TPH1/2 and GCHFR genes (not shown).

Upon sequencing the coding exons plus exon-intron boundaries of the SERT transporter SLC6A4 gene, we found in exon 3 at amino-acid codon 56 the heterozygous nucleotide variant c.167G $>C$, leading to a glycine to alanine exchange (also known as rs6355; see Fig. 1). The heterozygous SLC6A4 Gly56Ala allele was inherited from his mother. Besides this well known mutant allele, we should mention that additionally we found a homozygous SNP in the non-coding exon 2, c. $-185 \mathrm{C}>\mathrm{A}$ ( rs6354).

The SLC6A4 gene promoter sequence 5-HTTLPR showed the homozygous $\mathrm{L} / \mathrm{L}$ variant for the patient, whereas his mother had the $\mathrm{L} / \mathrm{S}$ and the father had the $\mathrm{L} / \mathrm{L}$ variants (Fig. $2 \mathrm{~A}$ ). As indicated in the

\section{SLC6A4}

Heterozygous c.167G>C p.Gly56Ala

C C TGGTGCGGGAGATGACACAC

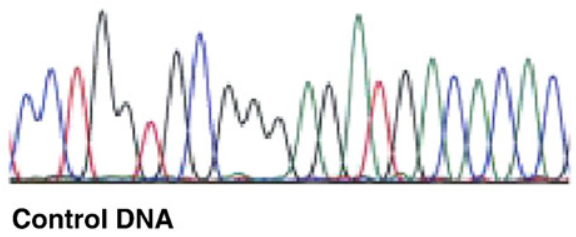

C C T G T T G G GNAGATGACACAC

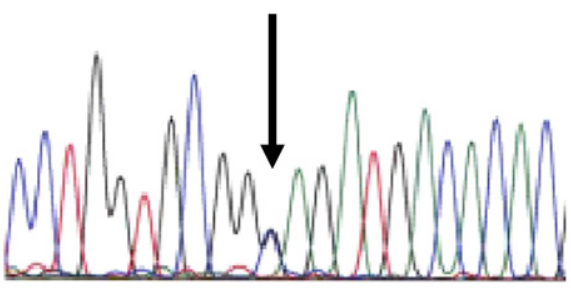

Genomic DNA from patient CM

Fig. 1. Detection of the heterozygous variant c.167G $>$ C (p.Gly56Ala) in exon 3 of the SLC6A4 gene in patient CM with atypical autism. For more details see Methods plus Supporting information and Table S1.

Introduction, the $\mathrm{L} / \mathrm{L}$ variant should lead to a lower serotonin concentration in the synaptic cleft than the other two variants [13].

As a final genetic alteration potentially influencing the activity of SERT, we analyzed the STin2 VNTR region in intron 2, and found the 9/10 variant for the patient, $10 / 12$ for his mother and $9 / 10$ for his father (Fig. 2B).

The mutations and variants found in the SLC6A4 gene in this family are summarized in Table 2. In summary, a patient with atypical autism was found to carry the heterozygous Gly56Ala allele in the SLC6A4 gene and exhibited low 5HIAA in CSF. Clinical improvement and normalization of serotonin turnover in the brain was found upon therapeutic intervention with 5-hydroxytryptophan/carbidopa. The implications of these findings will be discussed below.

\section{Discussion}

Allelic heterogeneity at the serotonin transporter gene locus (SLC6A4) was reported to confer susceptibility to autism and rigidcompulsive behavior. The patient we report here has a history of impaired motor and speech development and atypical autism or PDDNOS. Moreover, we found isolated low 5HIAA in CSF indicative for low extracellular serotonin levels in brain. As documented in previous

Table 1

CSF findings in patient CM with the heterozygous SLC6A4 Gly56Ala mutation.

\begin{tabular}{|c|c|c|c|c|c|}
\hline Patient & Age (yrs) & 5HIAA (nmol/l) & HVA (nmol/l) & HVA/5HIAA & Remarks \\
\hline \multirow[t]{3}{*}{$\mathrm{CM}$} & 3.7 & 102 & 372 & 3.6 & No treatment \\
\hline & 5.2 & 107 & 334 & 3.1 & 7 mg/kg/day 5-hydroxytryptophan \\
\hline & 5.9 & 186 & 367 & 2.0 & $\begin{array}{l}5 \mathrm{mg} / \mathrm{kg} / \text { day 5-hydroxytryptophan } \\
\text { and } 1 \mathrm{mg} / \mathrm{kg} / \text { day carbidopa }\end{array}$ \\
\hline \multirow[t]{2}{*}{ Ref. } & $2-4$ & $202(105-299)$ & $603(211-871)$ & $1.5-3.5$ & \\
\hline & $5-10$ & $133(88-178)$ & $523(144-801)$ & $1.5-3.5$ & \\
\hline
\end{tabular}

Reference values and ranges see also [21]. 
A

\section{5-HTTLPR}

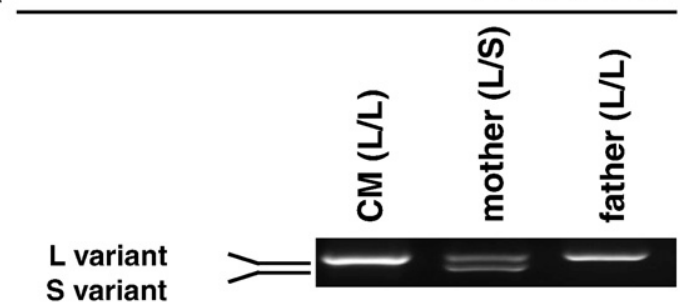

B

STin2 VNTR

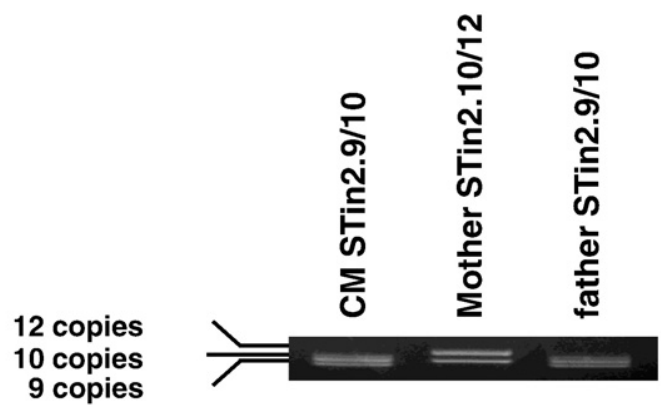

Fig. 2. SLC6A4 5-HTTLPR promoter and gene variants. (A) Amplification of 5-HTTLPR promoter variants. The PCR products at $523 \mathrm{bp}$ and $479 \mathrm{bp}$ indicate the present of the $\mathrm{L}$ (long) variant and the $\mathrm{S}$ (short) variant with a 44 bp deletion, respectively. (B) Analysis of the STin2 VNTR variants by PCR from patient CM and his parents. Amplification of the VNTR region in intron 2 (STin2) reveals the number of repetitive elements: 345 bp ( 9 copies), $360 \mathrm{bp}$ (10 copies) or $390 \mathrm{bp}$ (12 copies).

studies on autism [17], the presence of the Gly56Ala SLC6A4 mutation would be expected to lead to increased uptake and a serotonin overload within platelets, where the protein mutant is expressed. Furthermore, at the brain level, the consequent intracellular serotonin overload among SERT Gly56Ala heterozygous or homozygous subjects would be expected to increase serotonin re-uptake into pre-synaptic vesicles. Serotonin accumulation within pre-synaptic cells (or neighboring neurons and/or astrocytes) might predispose to secondary diminished serotonin metabolism and degradation by MAO enzymes. Evidence from functional neuro-imaging studies in autism has indicated low serotonin production within the brain between 2 and 5 years, while dietary tryptophan depletion aggravated the autistic behavior. However, the exact mechanism underlying these observations of diminished serotonin production in the brain has not been identified. Moreover, several authors have reported no difference for 5HIAA in CSF measured in autistic patients (for an overview see [17]), which is in contradiction to our routine determination of 5HIAA in CSF in patients with autistic disorders where we find a significant percentage of patients with low 5HIAA (unpublished observation). On the other hand, several other laboratories reported recently on isolated low 5HIAA level in CSF from patients with neurological disorders and neuro-psychiatric

Table 2

Polymorphisms and mutations in the SLC6A4 gene.

\begin{tabular}{llcl}
\hline Subject & 5-HTTLPR & STin2 VNTR & rs6355 (exon 3) \\
\hline Patient CM & L/L & $9 / 10$ & Heterozygous c.167G $>$ C (p.Gly56Ala) \\
Mother & L/S & $10 / 12$ & Heterozygous c.167G $>$ C (p.Gly56Ala) \\
Father & L/L & $9 / 10$ & Wild-type c.167G (p.Gly56) \\
\hline
\end{tabular}

Mutation designation is based on transcript ID: ENST00000394821 (Ensemble database) with 15 exons. The transcript length is $6335 \mathrm{bps}$, and the translation length is 672 residues. The numbering starts with 1 at A at the ATG-start codon. disturbances, including ASD (without identifying an underlying genetic cause) [25].

To find a genetic basis that could potentially explain the isolated low serotonin in the CNS (determined indirectly by the lowered 5HIAA concentration in CSF), we performed DNA mutation screening not only for the SERT transporter, encoded by the SLC6A4 gene, but also for other candidate genes that are directly involved in serotonin metabolism, such as TPH1, TPH2, and GCHFR. In addition to the described genetic variations in SLC6A4, there are other gene variants that may have an additional effect or modest influence on autism risk. These include de novo copy number variations [26], serotonergic receptor single nucleotide polymorphisms such as in the HTR3A gene [27], and also other genetic variants (for a recent overview see [28]). Since the impact of these genetic variations remains unclear or inconclusive, we did not collect these data. Our patient with atypical autism carrying the Gly56Ala/wt genotype in combination with the $\mathrm{L} / \mathrm{L}$ variant of the SLC6A4 promoter sequence is thought to have increased expression of both, the normal and mutated allele. We hypothesize that this will predispose to elevated serotonin re-uptake from synaptic clefts, and may be the deciding factor for the autistic phenotype. Furthermore, while the combination of the Ala56 allele with STin2 VNTR remains unclear regarding SERT function, we speculate that the L/S variant, in combination with the Gly56Ala/wt genotype, is the reason why the mother is a non-affected carrier. In addition, we have investigated the SLC6A4 gene for the Gly56Ala alteration in our current collection of samples from 137 patients with autistic disorder and identified the heterozygous situation in at least five other subjects. Although we do not know at this point the 5HIAA status in CSF for all five patients, at least one has lowered 5HIAA, indicating that low serotonin together with the SERT mutation may be more common in autism spectrum disorder (unpublished observation).

Physiologically, the low CSF 5HIAA levels and diminished urinary 5HIAA excretion in our patient indicate low serotonin turnover. The normalization of urinary 5HIAA excretion after a 5-hydroxytryptophan loading dose in our patient suggested diminished function of the first rate-limiting enzyme of serotonin synthesis, being the peripheral enzyme TPH1 converting tryptophan to 5-hydroxytryptophan. Likewise, the low 5HIAA value in spinal fluid with normalization after treatment by 5-hydroxytryptophan and carbidopa might also suggest low activity by neuronal TPH2. We speculate that an increased serotonin re-uptake by the protein mutant (Gly56Ala) of the serotonin transporters results in an initial overload of serotonin within neuronal tissue and might thus lead to indirect inhibition of serotonin synthesis with consequent reduction of the activity of the rate-limiting enzyme TPH2 (Fig. 3). Further investigation on the mechanisms explaining this indirect inhibition upon neuronal and peripheral TPH1 enzymes warrants subsequent studies. An alternative hypothesis is that the increased serotonin re-uptake initially leads to serotonin accumulation into pre-synaptic cytoplasm with increased transport into vesicles by the vesicular mono-amine transporter (VMAT) and increased degradation by aldehyde dehydrogenase and MAO enzymes. The subsequent enhanced catabolism might in time predispose to overall pre-synaptic serotonin depletion and low serotonin release. In transgenic mice, over-expressing the SERT protein low intraneuronal levels of serotonin and diminished release have been documented [29]. However, more complex adaptive changes mediated by up-regulation of pre-synaptic serotonin auto receptors in the brainstem raphe nuclei (5-HT1A) or at pre-synaptic nerve terminals (5-HT1B/1D) might also provide an explanation for low serotoninergic transmission at these synapses carrying the upregulated SERT protein [14,30].

In conclusion, our findings in a patient with speech delay and atypical autism associated with gain of function of the SLC6A4 serotonin transporter gene (Gly56Ala/wt) suggested a final stage of serotonin depletion or reduced serotonin turnover. Moreover, the important clinical and biochemical response following treatment by 


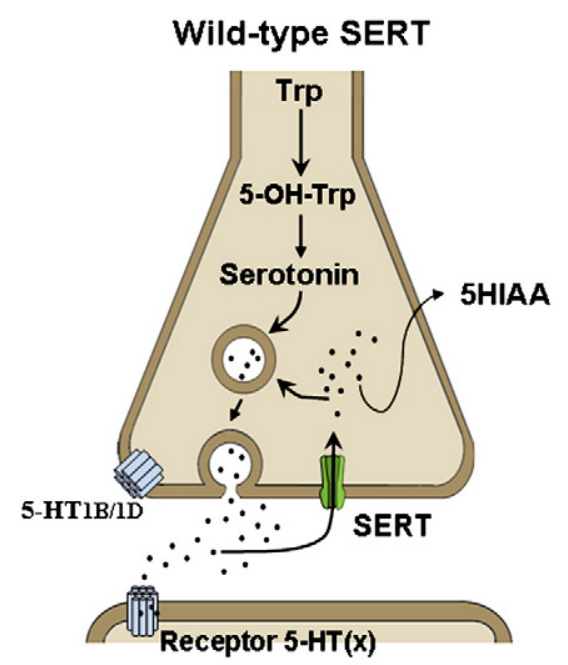

SERT heterozygous Gly56Ala mutation
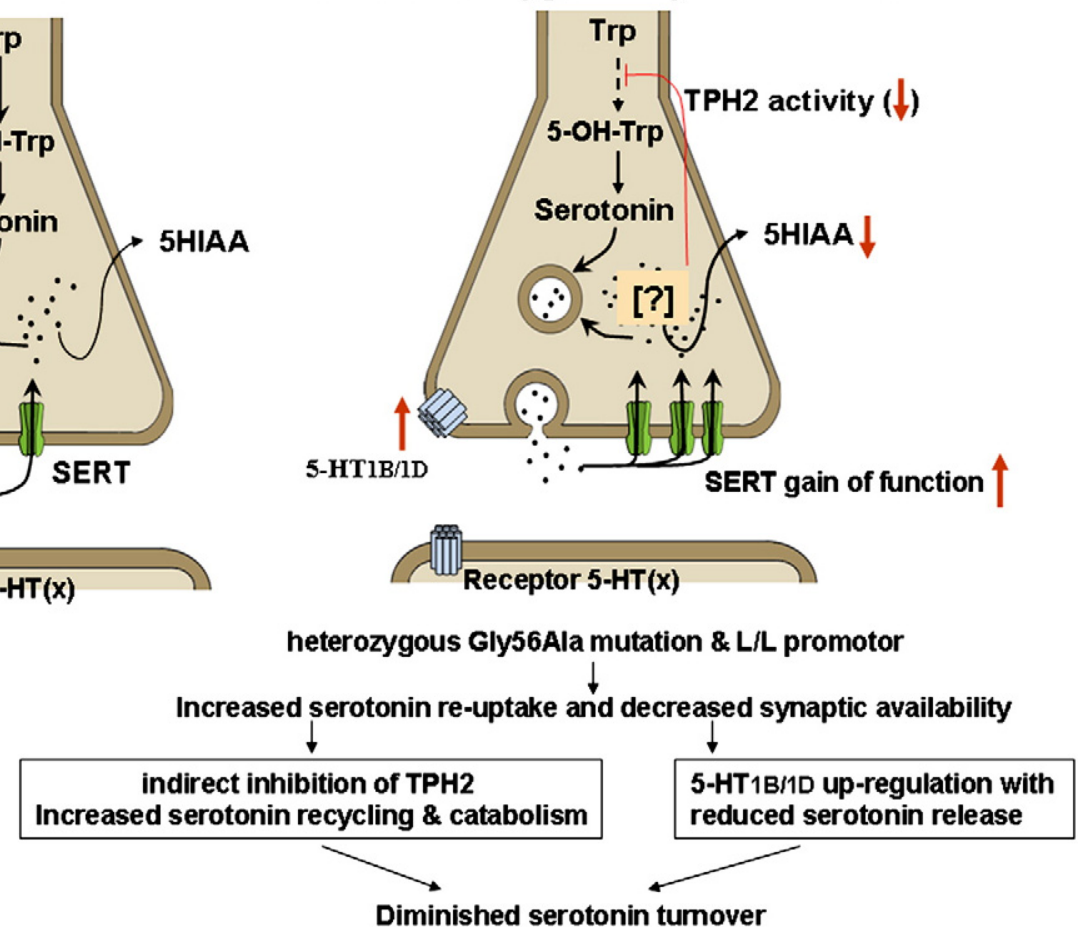

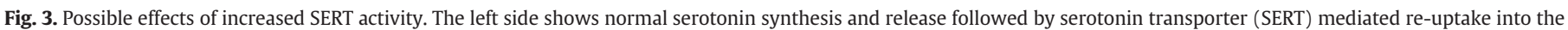

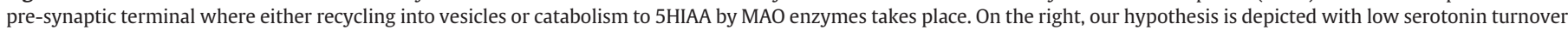

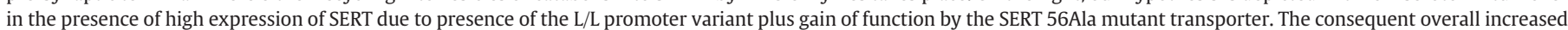

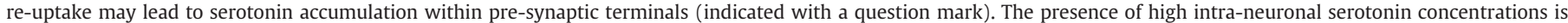

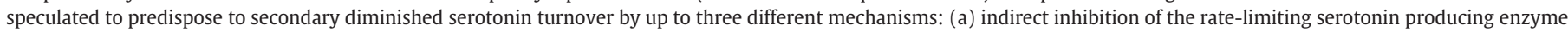

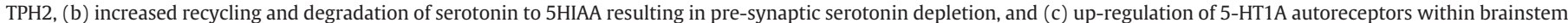

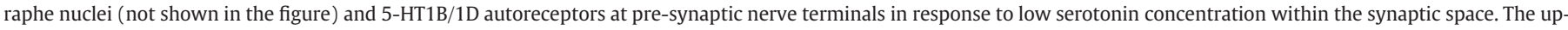

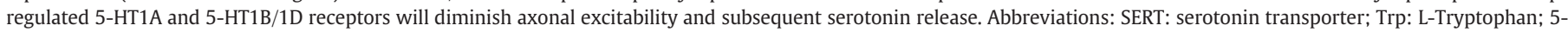

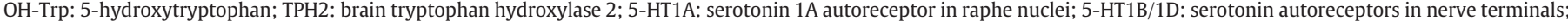
5HIAA: 5-hydroxyindoleacetic acid.

5-hydroxytryptophan and carbidopa supports our speculations about one possible pathophysiology of autism.

Supplementary data to this article can be found online at doi:10.1016/j.ymgme.2010.11.162.

\section{Acknowledgments}

This work was supported by grants from the Centre for Neuroscience Zürich (to B.T.), the Swiss National Science Foundation (to N.B. and B.T.), Novartis Foundation (to N.B.), and the Belgian National Fund for Scientific Research (FNRS) to V.R.

Competing interest: None.

\section{References}

[1] S.E. Levy, D.S. Mandell, R.T. Schultz, Autism, Lancet 374 (2009) 1627-1638.

[2] E.H. Cook, B.L. Leventhal, The serotonin system in autism, Curr. Opin. Pediatr. 8 (1996) 348-354.

[3] N.K. Burgess, T.L. Sweeten, W.M. McMahon, R.S. Fujinami, Hyperserotoninemia and altered immunity in autism, J. Autism Dev. Disord. 36 (2006) 697-704.

[4] D.C. Chugani, O. Muzik, M. Behen, R. Rothermel, J.J. Janisse, J. Lee, H.T. Chugani, Developmental changes in brain serotonin synthesis capacity in autistic and nonautistic children, Ann. Neurol. 45 (1999) 287-295.

[5] S.R. Chandana, M.E. Behen, C. Juhasz, O. Muzik, R.D. Rothermel, T.J. Mangner, P.K. Chakraborty, H.T. Chugani, D.C. Chugani, Significance of abnormalities in developmental trajectory and asymmetry of cortical serotonin synthesis in autism, Int. J. Dev. Neurosci. 23 (2005) 171-182.

[6] C.J. McDougle, S.T. Naylor, D.J. Cohen, G.K. Aghajanian, G.R. Heninger, L.H. Price, Effects of tryptophan depletion in drug-free adults with autistic disorder, Arch. Gen. Psychiatry 53 (1996) 993-1000.
[7] A. Kolevzon, K.A. Mathewson, E. Hollander, Selective serotonin reuptake inhibitors in autism: a review of efficacy and tolerability, J. Clin. Psychiatry 67 (2006) 407-414

[8] D.L. Murphy, M.A. Fox, K.R. Timpano, P.R. Moya, R. Ren-Patterson, A.M. Andrews, A. Holmes, K.P. Lesch, J.R. Wendland, How the serotonin story is being rewritten by new gene-based discoveries principally related to SLC6A4, the serotonin transporter gene, which functions to influence all cellular serotonin systems, Neuropharmacology 55 (2008) 932-960.

[9] D.I. Zafeiriou, A. Ververi, E. Vargiami, The serotonergic system: its role in pathogenesis and early developmental treatment of autism, Curr. Neuropharmacol. 7 (2009) 150-157.

[10] H.C. Prasad, J.A. Steiner, J.S. Sutcliffe, R.D. Blakely, Enhanced activity of human serotonin transporter variants associated with autism, Philos. Trans. R. Soc. Lond. B Biol. Sci. 364 (2009) 163-173.

[11] L.E. Esterling, T. Yoshikawa, G. Turner, J.A. Badner, D. Bengel, E.S. Gershon, W.H. Berrettini, S.D. Detera-Wadleigh, Serotonin transporter (5-HTT) gene and bipolar affective disorder, Am. J. Med. Genet. 81 (1998) 37-40.

[12] S. Sen, M. Burmeister, D. Ghosh, Meta-analysis of the association between a serotonin transporter promoter polymorphism (5-HTTLPR) and anxiety-related personality traits, Am. J. Med. Genet. B Neuropsychiatr. Genet. 127B (2004) 85-89.

[13] T. Canli, K.P. Lesch, Long story short: the serotonin transporter in emotion regulation and social cognition, Nat. Neurosci. 10 (2007) 1103-1109.

[14] K.A. Jennings, W.J. Sheward, A.J. Harmar, T. Sharp, Evidence that genetic variation in 5-HT transporter expression is linked to changes in 5-HT2A receptor function, Neuropharmacology 54 (2008) 776-783.

[15] J.S. Sutcliffe, R.J. Delahanty, H.C. Prasad, J.L. McCauley, Q. Han, L. Jiang, C. Li, S.E. Folstein, R.D. Blakely, Allelic heterogeneity at the serotonin transporter locus (SLC6A4) confers susceptibility to autism and rigid-compulsive behaviors, Am. J. Hum. Genet. 77 (2005) 265-279.

[16] A.D. Ogilvie, S. Battersby, V.J. Bubb, G. Fink, A.J. Harmar, G.M. Goodwim, C.A. Smith, Polymorphism in serotonin transporter gene associated with susceptibility to major depression, Lancet 347 (1996) 731-733.

[17] K.S. Lam, M.G. Aman, L.E. Arnold, Neurochemical correlates of autistic disorder: a review of the literature, Res. Dev. Disabil. 27 (2006) 254-289.

[18] V.T. Ramaekers, J. Senderek, M. Hausler, M. Haring, N. Abeling, K. Zerres, C. Bergmann, G. Heimann, N. Blau, A novel neurodevelopmental syndrome responsive to 5hydroxytryptophan and carbidopa, Mol. Genet. Metab. 73 (2001) 179-187. 
[19] J.A. Laros, P.J. Tellegen, Construction and validation of the SON-R $51 / 2$ - 17, the Snijders-Oomen non-verbal intelligence test Thesis (Proefschrift) (1991) Editors: Wolters-Noordhoff. ISBN 90-01-52962-52963. Groningen.

[20] L. Bonafe, B. Thöny, W. Leimbacher, L. Kierat, N. Blau, Diagnosis of doparesponsive dystonia and other tetrahydrobiopterin disorders by the study of biopterin metabolism in fibroblasts, Clin. Chem. 47 (2001) 477-485.

[21] N. Blau, L. Bonafe, M.E. Blaskovics, Disorders of phenylalanine and tetrahydrobiopterin metabolism, in: N. Blau, M. Duran, M.E. Blaskovics, K.M. Gibson (Eds.), Physician's Guide to the Laboratory Diagnosis of Metabolic Diseases, 2nd Edition, Springer, 2003, pp. 89-106.

[22] D.J. Walther, J.U. Peter, S. Bashammakh, H. Hortnagl, M. Voits, H. Fink, M. Bader, Synthesis of serotonin by a second tryptophan hydroxylase isoform, Science 299 (2003) 76.

[23] D.J. Walther, M. Bader, A unique central tryptophan hydroxylase isoform, Biochem. Pharmacol. 66 (2003) 1673-1680.

[24] G. Kapatos, K. Hirayama, M. Shimoji, S. Milstien, GTP cyclohydrolase I feedback regulatory protein is expressed in serotonin neurons and regulates tetrahydrobiopterin biosynthesis, J. Neurochem. 72 (1999) 669-675.

[25] E. De Grandis, M. Serrano, B. Perez-Duenas, A. Ormazabal, R. Montero, E. Veneselli, M. Pineda, V. Gonzalez, F. Sanmarti, C. Fons, A. Sans, B. Cormand, L. Puelles, A. Alonso, J. Campistol, R. Artuch, A. Garcia-Cazorla, Cerebrospinal fluid alterations of the serotonin product, 5-hydroxyindolacetic acid, in neurological disorders, J. Inherit. Metab. Dis. 33 (2010) 803-809.

[26] J. Sebat, B. Lakshmi, D. Malhotra, J. Troge, C. Lese-Martin, T. Walsh, B. Yamrom, S. Yoon, A. Krasnitz, J. Kendall, A. Leotta, D. Pai, R. Zhang, Y.H. Lee, J. Hicks, S.J. Spence, A.T. Lee, K. Puura, T. Lehtimaki, D. Ledbetter, P.K. Gregersen, J. Bregman, J.S. Sutcliffe, V. Jobanputra, W. Chung, D. Warburton, M.C. King, D. Skuse, D.H. Geschwind, T.C. Gilliam, K. Ye, M. Wigler, Strong association of de novo copy number mutations with autism, Science 316 (2007) 445-449.

[27] B.M. Anderson, N.C. Schnetz-Boutaud, J. Bartlett, A.M. Wotawa, H.H. Wright, R.K. Abramson, M.L. Cuccaro, J.R. Gilbert, M.A. Pericak-Vance, J.L. Haines, Examination of association of genes in the serotonin system to autism, Neurogenetics 10 (2009) 209-216.

[28] U.M. D'Souza, I.W. Craig, Functional genetic polymorphisms in serotonin and dopamine gene systems and their significance in behavioural disorders, Prog. Brain Res. 172 (2008) 73-98.

[29] K.A. Jennings, M.K. Loder, W.J. Sheward, Q. Pei, R.M. Deacon, M.A. Benson, H.J. Olverman, N.D. Hastie, A.J. Harmar, S. Shen, T. Sharp, Increased expression of the 5-HT transporter confers a low-anxiety phenotype linked to decreased 5-HT transmission, J. Neurosci. 26 (2006) 8955-8964.

[30] P. Celada, M. Puig, M. Amargos-Bosch, A. Adell, F. Artigas, The therapeutic role of 5-HT1A and 5-HT2A receptors in depression, J. Psychiatry Neurosci. 29 (2004) 252-265. 